\title{
BIRDS OF BRIER ISLAND
}

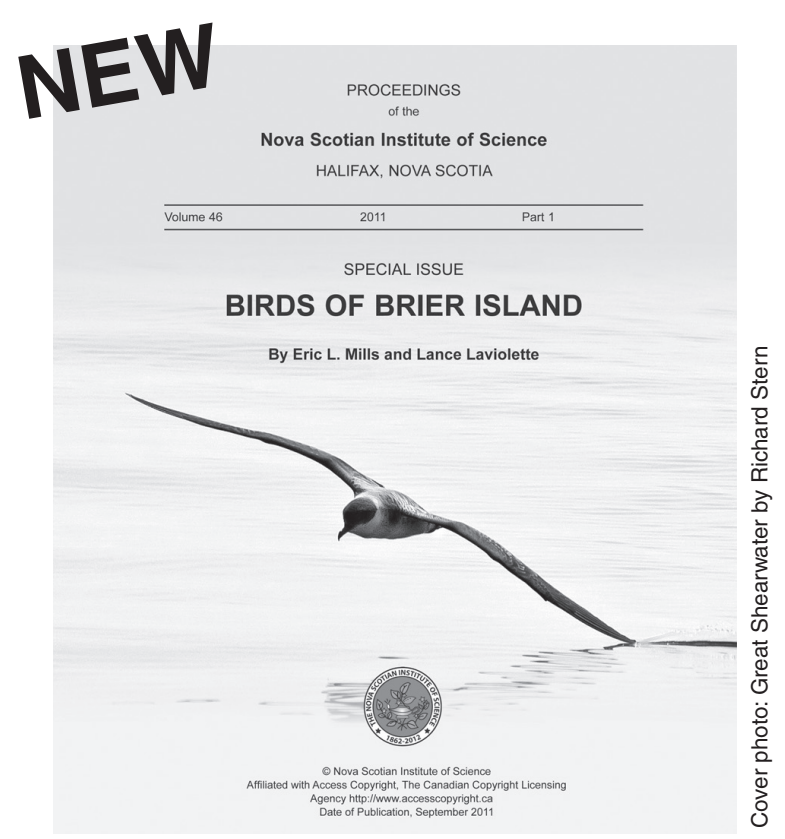

Birds of Brier Island by Eric L. Mills \& Lance Laviolette. Sept. 2011; gives a fascinating overview of the visiting and nesting birds that have travelled through Nova Scotia's Bay of Fundy region and made a stopover on Brier Island. 107pp, ill. $8.5 \times 11$ in; softcover. Published as a special issue - Vol. 46, Part 1, of the Proceedings of the Nova Scotian Institute of Science.

Price: CDN\$25.00 + postage and handling.

2011 postage \& handling charges per copy (CDN dollars) : Within Canada: add $\$ 5.00$ US orders: add $\$ 8.00$.

If you wish to purchase multiple copies, please contact Carol Richardson (clrichar@dal.ca) about the cost of postage and handling.

To avoid postage fees, copies of the book can also be purchased in person at the Killam Library Research Services office, 3rd floor, Killam Library, 6225 University Ave., Halifax, Nova Scotia.

See next page for Order Form. 


\section{Order Form}

Please send me copies of Birds of Brier Island.

$\$ 25.00$ per copy $=$

Add postage and handling $=$

Total $=$

$\$$

Name:

Address:

Province/State:

Country:

Postal or zip code:

$\square \quad$ Please send to my Dalhousie campus office (saves postage)

Email address:

Please make cheque payable to: Nova Scotian Institute of Science

Mail order form and payment to:

Nova Scotian Institute of Science

c/o Killam Library, Dalhousie University, 6225 University Avenue

P. O. Box 15000, Halifax, Nova Scotia, Canada B3H 4R2

PLEASE PHOTOCOPY \& FILL OUT AND FORWARD TO ADDRESS ABOVE. 